The emotional basis of the ideal multilingual self: the case of simultaneous language learners in China

Meng Liu*

Faculty of Education, University of Cambridge, Cambridge, UK

Link to the published version:

https://www.tandfonline.com/eprint/YSEK7SZ7ZJ8ABN8UCQEA/full?target=10. $\underline{1080 / 01434632.2020 .1755294}$ 


\section{The emotional basis of the ideal multilingual self: the case of simultaneous language learners in China}

The present study contributes to the field of L2 motivation by exploring the link between emotional experience in language learning and motivational self from a multilingual perspective. Specifically, it evaluated the empirical support for the validity of the ideal multilingual self on simultaneous language learners in China and assessed the relationship between emotional experience (positive and negative) in language learning and the ideal multilingual self using structural equation modelling. Five hundred and twenty-three learners of English and languages other than English (LOTEs) in Chinese universities participated in the survey study. Findings established the construct validity of the ideal multilingual self and unveiled the significance and complexity of the link between emotion and motivation. Specifically, learners reported largely similar positive experiences in learning English and LOTEs and positive emotions in both languages were positively linked, with equal magnitude, to the ideal multilingual self. The patterns involving negative emotions were less consistent as learners reported differing negative experiences in learning the two languages and only negative emotion in English learning was negatively linked to the ideal multilingual self. The complexity of patterns brings forth a more nuanced understanding of the connection between emotion and multilingual motivation with pedagogical implications. Keywords: multilingualism; L2MSS; emotion; motivation; 


\section{Introduction}

L2 motivational research has an 'emotional deficit' (Dörnyei \& Ryan, 2015, p. 10).

Despite motivation being labelled as an 'affective' variable, the relationship between emotion and L2 motivation often remains inexplicit in empirical research. Nevertheless, 'emotion just might be the fundamental basis of motivation, one deserving far greater attention in the language learning domain' (MacIntyre, 2002, p. 45). Echoing this sentiment is the call for more research on the role of emotion in future self-guides in the anthology of research on motivation and language identity (Dörnyei \& Ushioda, 2009; MacIntyre et al., 2009). Owing to the positive psychology movement in applied linguistics (Dewaele et al., 2019; Dewaele \& Li, 2020; MacIntyre, Gregersen, et al., 2019; MacIntyre \& Mercer, 2014), this situation is improving as more attention is being paid not only to positive emotion but also to its interaction with negative emotion (Dewaele \& MacIntyre, 2014, 2016). Recently, there has been a further advance in that some initial effort has been made to explicitly approach the relationship between emotion and motivation by systematically investigating a full range of emotions, not just one or two key ones, in conjunction with motivational variables, including L2 selves in order to paint a more comprehensive picture of the emotional underpinnings of L2 motivation (MacIntyre, Dewaele, et al., 2019; MacIntyre \& Vincze, 2017). In light of this initial development, it is necessary to continue the effort to further understand how emotions supply future self-guides with motivational potency.

In the meantime, appeals have been reiterated to address the monolingual bias that has been prevalent in SLA in general (e.g., May, 2019) and L2 motivational research in particular (e.g., Dörnyei \& Al-Hoorie, 2017; Henry, 2010). Taking the L2 motivational self system (L2MSS) (Dörnyei, 2009) as an instance, learners' aspiration to become competent users of language (i.e., the ideal L2 self) has long been conceptualised from 
the perspective of 'monolingual learners...engaged in learning a single L2' (Henry, 2010, p. 151). The neglect of the full range of a person's linguistic repertoire may risk distorting the multilingual experience that learners find themselves in. For instance, learners of French or German in China, as in many places in the world, usually already have a longer history of English learning. Recently in China, there has been a shift in educational policy to promote LOTE programmes, resulting in a growing number of learners engaged in learning multiple foreign languages (Gao \& Zheng, 2019).

Neglecting the often concurrent learning processes of multiple languages may conceal a potential source of motivation that represents a learner's aspiration to become a user of more than one foreign language (i.e., the ideal multilingual self) (Busse, 2017; Henry, 2017; Henry \& Thorsen, 2018; Ushioda, 2017). Therefore, it is imperative to develop a more nuanced understanding of motivation from a multilingual perspective.

As a response to calls to address the emotional deficit and the monolingual bias in L2 motivational research (Dörnyei \& Ryan, 2015; Henry, 2017; MacIntyre, 2002; Ushioda, 2017), this study aims to examine the link between emotion and motivation from a multilingual perspective. Specifically, the study was set in the context of simultaneous language learning, as it allowed for a more nuanced understanding of different emotional experiences in learning different languages and whether they differ in relation to multilingual motivation.

\section{Review of the literature}

\section{L2MSS and emotion}

Drawing on possible selves theory (Markus \& Nurius, 1986), self-discrepancy theory (Higgins, 1987) and the socio-educational model (Gardner, 1985, 2010), Dörnyei (2005, 2009) developed the L2MSS to account for the motivation to learn a foreign language. 
The model is composed of three parts: The ideal L2 self (the future self imagery as a competent L2 user based on one's own aspiration), the ought-to L2 self (the future self imagery as a competent L2 user based on one's obligation or others' expectation) and the L2 learning experience (experience concerning aspects of the learning environment such as teachers, curriculum and peers). Validated across a variety of contexts such as China, Hungary and Japan, the L2MSS has become the dominant model in L2 motivational research (Boo et al., 2015).

Consistent with the cognitive revolution in mainstream psychology (Dörnyei, 2005) and the coginitivist root of SLA (Dörnyei \& Ryan, 2015), the L2MSS has accorded cognition, not emotion, the central explanatory role. Nevertheless, emotion could be the key to the motivational potency of future self imagery, rendering it more than merely 'cold cognition' (MacIntyre et al., 2009, p. 47). One way that emotion is linked to possible selves is though the imagery component, because 'one the key roles of the sensation generated by experiential images is exactly to evoke emotional responses' (Dörnyei \& Ushioda, 2009, p. 352). Drawing on Fredrickson’s broaden-and-build theory $(2001,2003,2004)$ that differentiates positive emotion which broadens perspective and builds resources from negative emotion that narrows down focus, MacIntyre and Gregersen (2012) further specified that the motivational power of future self-guides for language learning is largely derived from anticipatory emotions 'emotions experienced due to the prospect of a desirable or undesirable future event', i.e., emotions 'currently experienced due to something that could happen in the future' (Baumgartner et al., 2008, p. 685). Both positive and negative emotions are essential to energising the effort to reduce the discrepancy between learners' current and future selves. Another and less-examined way that emotion plays a role in motivational self is through language learning experience (MacIntyre et al., 2009). Emotions permeate 
learners' day-to-day lives and are inherently motivating in the sense that they guide thoughts and behaviours either deliberately or unconsciously. In a recent synthesis of theories and empirical evidence dedicated to the motivational qualities of emotions, MacIntyre and colleagues argued that emotion encompasses feelings, bodily responses, sense of purpose and expressive behaviours and thereby plays the role of motivating one's adaptive responses to significant events in daily life (2020). Specifically, positive emotion serves the purpose of enhancing one's long term well-being and thriving whereas negative emotion is oriented towards problem solving through narrowing attentional focus to the present danger or threat (e.g., Conway et al., 2013; Fredrickson, 2004). Therefore, the emotional experiences learners go through, such as anxiety and enjoyment, in the language learning journey would have significant implications for their language learning motivation, including future self-guides (MacIntyre, Dewaele, et al., 2019; MacIntyre et al., 2020; MacIntyre \& Vincze, 2017). Drawing on evidence from a learner's Russian learning journey, MacIntyre and colleagues (2009) posited a developmental process by which learning progress enhanced the vision of the future self and thus the motivation. Again, the emotions experienced in the language learning process could very well be key to the on-going dynamism between vision and motivation.

Empirically, emotion has rarely been the primary focus in motivational research but there has been some evidence concerning the relationship between negative emotion and the ideal L2 self, albeit still inconclusive. Anxiety was found to display a negative relation to the ideal English self in a study on Iranian learners (Papi, 2010) and to the ideal LOTE self in a study on speakers of English as L1 (Sugita McEown et al., 2014). Nevertheless, in another study on Iranian learners a non-significant relationship was uncovered (Teimouri, 2016). 
It was only recently that some researchers started investigating the relationship between positive emotion and the ideal L2 self (MacIntyre \& Vincze, 2017; Teimouri, 2016) and a more consistent pattern seems to emerge. Ideal L2 self was found to positively predict joy in language learning (Teimouri, 2016) and displayed a consistently positive relation to a wide variety of positive emotions (MacIntyre \& Vincze, 2017). It is worth noting that only very few studies incorporated a wide range of emotions, both positive and negative, to allow for a more comprehensive picture to be drawn (MacIntyre, Dewaele, et al., 2019; MacIntyre \& Vincze, 2017). In a study of 182 Italian secondary school learners of L2 German (MacIntyre \& Vincze, 2017) 19 emotions $^{1}$ were examined in relation to a variety of learner variables, including the ideal L2 self. All 10 positive emotions were positively correlated with the ideal L2 self to a moderate degree while the nine negative emotions were negatively correlated to a lesser degree.

\section{Simultaneous language learning motivation}

Recently, appeals have been made to incorporate LOTEs into L2 motivation research to redress the monolingual bias and retheorise L2 learning motivation (Dörnyei \& AlHoorie, 2017; Ushioda, 2017). This is because the global status and high instrumental value of English is almost unparalleled in LOTEs, a contrast that has significant implications for multilingual learning (e.g., Dörnyei \& Csizér, 2002; Henry, 2010, 2011). While there is an increasing amount of research on LOTEs learning (See Mendoza \& Phung, 2019 for a review), the phenomenon of simultaneous language learning deserves more attention as it facilitates a holistic understanding of the motivational process involving more than one language. Evidence from earlier research

\footnotetext{
${ }^{1}$ In the original English version of the questionnaire, there were 10 positive and 10 negative emotions. Two negative emotions converged on the same terms when translated into Italian, resulting in 19 emotions in the study.
} 
(Dörnyei et al., 2006) has revealed that motivation for foreign languages is unevenly distributed, with English potentially impeding other foreign languages (Dörnyei \& Csizér, 2002). Particularly for learners of two or more languages, separate self-concepts coexist, English may serve as a 'yardstick' or referential norm for the formation of LOTE selves and may thus pose threat to a LOTE self (Henry, 2010, 2011). A negative influence of ideal English self on different motivational aspects involving LOTEs was found in Hungarian learners of two foreign languages (Csizér \& Lukács, 2010) whereas in other cases English did not necessarily weaken interest in LOTEs (Siridetkoon \& Dewaele, 2018).

\section{The ideal multilingual self}

In light of the complex relationship between global English and lower-profile LOTEs, a retheorisation of L2 motivation from its traditional monolingual norm to a more inclusive multilingual model is needed. Foreign language learners are thus reconceptualised from learners developing a single L2 to learners developing a linguistic repertoire of more than one language (Busse, 2017; Henry, 2017; Ushioda, 2017). Drawing on L2MSS, the complex dynamic systems perspective (e.g., Dörnyei et al., 2015) and multilingualism research (e.g., the concept of 'multilinguality' in Aronin, 2016), Henry (2017) proposed a 'multilingual motivational self system' (p.552) nested in a multilingual identity system. The multilingual identity system encompasses 'everything that results from using and learning several languages, both in the present and also potentially in the future', including 'perceptions, attitudes and personal life scenarios, both real and possible' (Aronin, 2016, p. 145). Within this system, the multilingual motivational self system is composed of different multilingual self-guides, emergent from interactions of lower-level separate selves in different languages. The 
nature of such interactions (e.g., antagonistic or harmonious) determines the type of multilingual guides. The 'ideal multilingual self' is emergent from positive interactions between selves of different languages and represents the learner's aspiration to be/become multilingual. This self-guide is of practical significance as it could redress the imbalance between global English and LOTEs and function as a motivational source additional to motivations for specific languages.

Some initial empirical evidence was found to support such theorisation in that ideal multilingual self displayed discriminant validity from the ideal LOTE self and had an indirect effect on intended effort for LOTE learning (Henry \& Thorsen, 2018). In European contexts, the conceptually similar plurilingual identity was corroborated by evidence from learners of more than one foreign language (Busse, 2017) and a multilingual-identity-based pedagogy has been proposed to enhance LOTEs learning motivation (Fisher et al., 2018). In Asian contexts such as mainland China, initial research on simultaneous language learning also uncovered some learners' aspiration to become multilingual or diversify their linguistic repertoire (Z. Wang \& Zheng, 2019; Zheng et al., 2019). Still, learners' motivation to become multilingual is under-explored and its relationship to other key factors such as emotion remains unknown.

\section{The present study}

This study aimed to explore the link between emotion and motivation from a multilingual perspective. Specifically, simultaneous learners of English and LOTEs were targeted to allow for a more nuanced understanding: The role of both positive and negative emotion experienced in English and LOTEs learning in ideal multilingual self was examined and comparisons were made to assess whether and how the relationships might differ depending on the languages being learned (English or LOTEs). 
Considering the paucity of previous research that empirically and formally examined the construct of the ideal multilingual self in China, this study also aimed to assess the construct validity of the ideal multilingual self (cf. Henry \& Thorsen, 2018 for construct validity in the Sweden context on secondary school learners), as a prerequisite to the examination of relationships among emotional and motivational constructs.

Accordingly, the research questions are presented below:

RQ1 To what extent can convergent and discriminant validity of the ideal multilingual self be established?

Given that the current study is one of the first to empirically examine the construct of the ideal multilingual self on university students in China, it stands to reason to first assess the extent to which this construct is applicable to the Chinese context. Specifically, both convergent and discriminant validity were evaluated, in the form of confirmatory factor analysis (CFA). Sufficient validity was established before proceeding to the following research questions.

RQ2 To what extent do positive and negative emotional experiences in English (L2) and LOTEs (L3) learning predict the ideal multilingual self?

With construct validity established, relationships among emotional and motivational constructs were examined. Specifically, past emotional experiences in language learning were modelled as predictors of the ideal multilingual self, the higher-order multilingual self-guide. Based on previous research (MacIntyre, Dewaele, et al., 2019; MacIntyre \& Vincze, 2017; Papi, 2010; Sugita McEown et al., 2014), positive emotion was hypothesised to positively predict the ideal multilingual self and negative emotion negatively so $(\gamma 1-\gamma 4$; Figure 1$)$. 


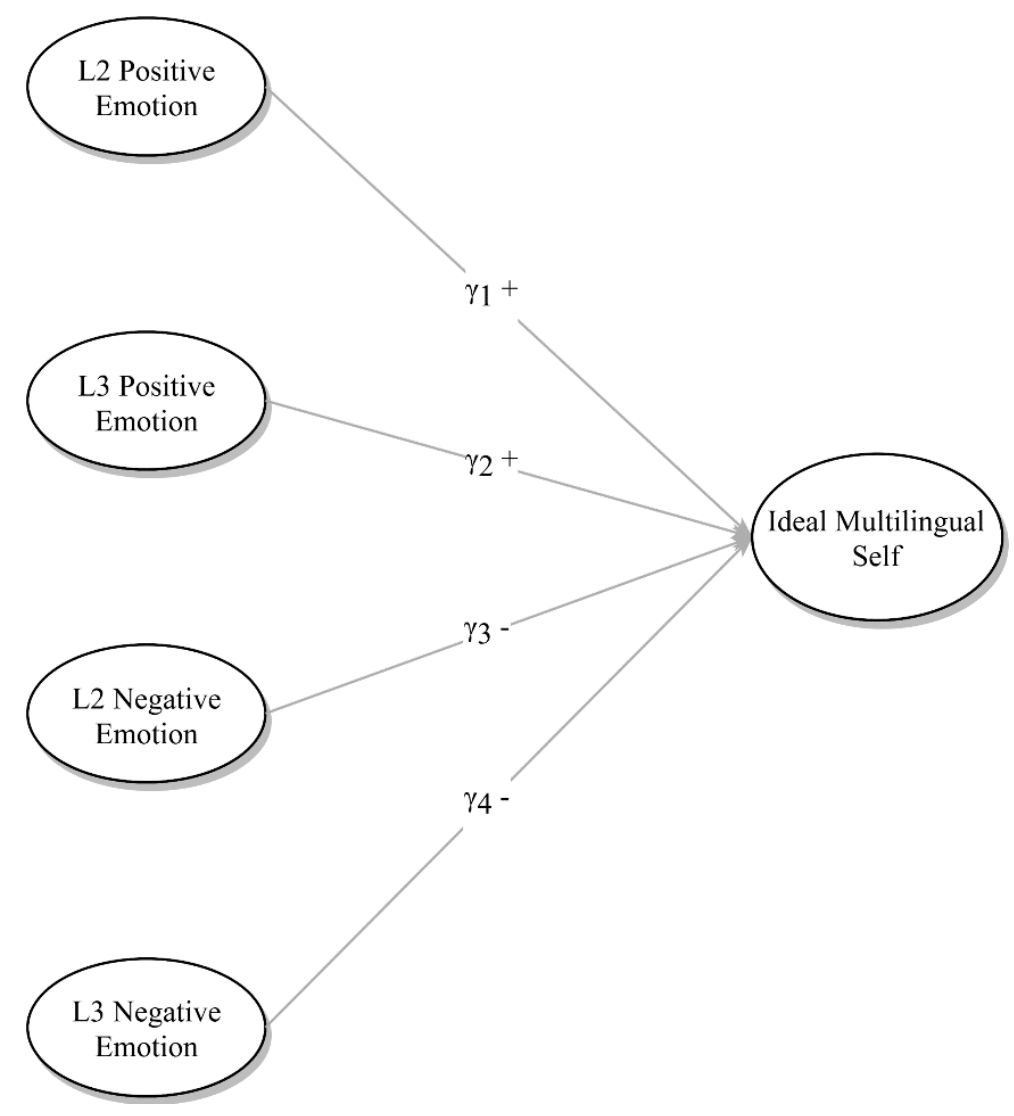

Figure 1 Schematic representation of the SEM model.

RQ3 Are positive and negative emotions in English (L2) and LOTEs (L3) learning equally predictive of the ideal multilingual self?

A further enquiry is to what extent different emotions in different languages may differ in their links to the ideal multilingual self. Specifically, the strength of the links between positive emotion and the ideal multilingual self was compared with respect to English (L2) and LOTEs (L3) (null hypothesis: $\gamma 1=\gamma 2$ ). Similarly, the strength of the links between negative emotion and the ideal multilingual self was compared (null hypothesis: $\gamma 3=\gamma 4$ ). It should be noted that there was little evidence available regarding the comparison of the role of emotion in learning English and LOTEs in relation to multilingual self in the same group of students but theory and some initial evidence (e.g., Busse, 2017; Dörnyei \& Al-Hoorie, 2017; Henry, 2010; Ushioda, 2017) suggest 
drastic difference between English and LOTEs with respect to a number of factors such as language learning attitude and motivation. Therefore, the predictive power of emotions in English was hypothesised to be different from that in LOTEs.

\section{Methods}

\section{The context}

This research is situated in the context of English major programmes in ordinary Chinese universities. English major students constitute a significant part of the student body in tertiary education, with 994 out of 1,148 full-time ordinary institutions of higher education offering English major programmes and a student population of over 570,000 (J. Wang, 2015). More importantly, this student cohort constitutes a potentially illuminating case of learning multiple foreign languages. With LOTE (L3) being a compulsory part of the English major curriculum, it is expected that English majors, after four semesters' learning (256 credit hours), will reach a level equivalent to that of a third-year student in the corresponding LOTE major (Zhao \& Li, 2014). In other words, simultaneous language learning is an integral part of their university education.

\section{Participants}

The sample in this study consisted of 523 undergraduate students $\left(\mathrm{m}=54, \mathrm{f}=469^{2}\right.$, age $(\mathrm{M}=20.8 \mathrm{SD}=0.97))$ who were studying English while simultaneous learning an L3 $($ French $=439$, German $=84)$ at the time of the survey. Of the participants, $86.6 \%$ had been learning English for over 10 years. The history of learning L3 varied from one to four semesters $($ one $=203$, two $=133$, three $=135$, four $=52$ ). Of the participants, $2.3 \%$

\footnotetext{
${ }^{2}$ It should be noted that the gender composition of language programmes (i.e., primarily composed of female) is not uncommon in university language programmes in China as observed in all schools in the study. Therefore, gender difference is beyond the scope of this study.
} 
had previous experience of learning French or German before university whereas $28.3 \%$ had learned another foreign language for a period of one month to three years (mainly less than six months).

\section{Instruments}

The study was conducted using the following instruments to measure the following constructs:

(1) Positive and negative emotion in language learning (English as L2 \& LOTEs as L3). Positive emotion and negative emotion were measured by the frequency of experiencing a variety of emotions in the past language learning experience. Specifically, participants were asked to indicate how often they had experienced a certain emotion during the previous process of language learning ((Instruction: 'The scale contains a number of words that describe different feelings, please recall and indicate how often you experienced them in your past [name of the language] learning experience.'). Ten positive and 10 negative emotions, adapted from Fredrickson's modified Differential Emotions Scale (2013), were used to represent the range of emotions experienced during language learning (Table 1). Each emotion was presented in the form of a synonymously worded trio. For instance, 'amused, fun-loving, or silly' were grouped to better capture the emotion 'amusement'. Following MacIntyre and Vincze (2017), five response options ( 1 = 'never', $2=$ 'rarely', $3=$ 'sometimes', $4=$ 'often', $5=$ 'every day') were used. Both the Chinese translation and the original English trios were kept in the questionnaire based on feedback from the initial piloting. 
(2) The ideal multilingual self. Referencing previous research on the ideal L2 self (Dörnyei \& Taguchi, 2010) and ideal multilingual self (Henry \& Thorsen, 2018), the ideal multilingual self was measured using six items (Table 1). Participants were asked to indicate to what extent they agreed that the statements described themselves. Six response options ( $1=$ 'strongly disagree', 2 = 'disagree', 3 = 'somewhat disagree', 4 = 'somewhat agree', 5 $=$ 'agree', $6=$ 'strongly agree') were provided.

\section{Piloting and procedures}

Drawing on previous research, the instruments were first compiled in English and reviewed by an expert in applied linguistics (L1 English). The researcher (L1 Chinese) then translated the whole questionnaire into Chinese. The Chinese version was reviewed and refined by a panel of five L1 Chinese students in English major programmes in China. To ensure the reliability and validity of the instruments, a formal pilot study on a sample $(\mathrm{N}=108)$ from the same target population was conducted in April 2019, after which the data in this article (N=523) were collected in June and September 2019.

Purposive sampling was adopted to obtain the samples in this study to represent English major students simultaneously studying European languages at ordinary universities in China. All participants in the main sample were from four ordinary universities with similar rankings (second and third tier) and student intake (university $\mathrm{A}=112$, university $B=83$, university $C=242$, university $D=86$ ) in four cities in eastern China. The pilot sample was collected from a different university with similar characteristics. Non-key universities were specifically targeted because they are comparatively less represented in research literature yet constitute a greater proportion of university students in China. 
Questionnaires were administered during class time with the assistance of L3 classroom teachers via the Qualtrics platform. Informed consent was obtained individually at the beginning of each questionnaire.

\section{Data analysis}

Data screening and assumption checks were conducted using the software R (version 3.6.2; R Core Team, 2020). Structural equation modelling (SEM) was adopted as the main analytical technique and the analyses were conducted using Mplus 8.3 (L. Muthén \& Muthén, 2019).

To address RQ1, confirmatory factor analysis (CFA) was utilised to check the construct validity. Specifically, a variety of indicators were computed to evaluate the convergent and divergent validity of the constructs used in the analysis. Convergent validity indicates the extent to which questionnaire items could represent the latent construct. It was judged on the basis of three indicators, namely factor loadings (no less than .50), construct reliability and average variance extracted (AVE). It should be noted that the conventional Cronbach's $\alpha$ as an indicator of construct reliability may not be appropriate in latent modelling context as it assumes $\tau$-equivalence (i.e. equal factor loadings; Raykov, 2004) and Jöreskog's $\rho$ was used as the more appropriate indicator (Fornell \& Larcker, 1981), with .70 or greater as an indication of sufficient reliability (Hair et al., 2013). AVE reflects whether variance explained by the latent construct is greater than the variance due to measurement error, with a value of .50 or higher as high validity (Fornell \& Larcker, 1981). Discriminant validity is indicative of whether latent constructs are sufficiently distinguishable from each other. One indicator of discriminant validity is latent construct correlation and values should be less than .85 for sufficient validity (Brown, 2015). Another rule of thumb is for AVE values to be 
greater than the square of the correlation between the corresponding factors, indicating that the construct explains more of its own items than it shares with other constructs (Hair et al., 2013).

Structural equation modelling (SEM) was conducted to address the other two research questions using Mplus 8.3. For RQ2, SEM was utilised to examine the relationships among latent variables. Model fit was checked against the most common goodness-offit indices in SEM analysis: Comparative Fit Index (CFI), Tucker-Lewis Index (TLI), Root Mean Square Error of Approximation (RMSEA) and Standardised Root Mean Square Residual (SRMR). Values of good model fit were set up at CFI and TLI close to or greater than .95 , RMSEA close to or less than .06 as well as SRMR close to or less than .08 (Hu \& Bentler, 1999). For RQ3, chi-square difference test of nested models was conducted (using the DIFFTEST function in Mplus 8.3) by comparing chi-square statistics between the original model and the nested model with equality constraints on structural path coefficients.

\section{Results}

\section{Preliminary analyses}

Descriptive analyses were run on all 46 items to obtain a preliminary understanding of the data (Table 1, Figure 2) and some interesting patterns were identified with respect to the emotional items. Comparing the responses of experiencing positive and negative emotion (Figure 2, Table 1), the overall pattern suggests more frequent positive emotional experience than negative emotional experience in both languages, meaning that for both English and LOTEs learning, learners' overall experience was noticeably more positive than negative. For all 10 positive emotions and the majority of negative emotions (Figure 2), the frequency of experience was slightly higher in English learning 
than in LOTEs learning, with an exception being 'fear', which was experienced more frequently in LOTEs learning than in English learning. This means that students were slightly more emotionally engaged, both positively and negatively, in the learning of English than LOTEs. Ranking the mean scores of individual emotions in descending order and comparing across the two languages (Table 1), the patterns are largely uniform with respect to positive emotion, with the exception of 'awe' being in a higher rank in English learning than in LOTEs learning. The ranking patterns concerning negative emotion are more divergent between the two languages, with only the top one ('stress') and bottom four emotions ('guilt', 'hate', 'disgust', 'contempt') being the same in rank (Table 1). These findings indicate that students experienced positive emotion largely similarly in learning the two languages, but they experienced negative emotion more differently in learning the two languages.

Table 1 Descriptive statistics

\begin{tabular}{|c|c|c|c|c|c|c|}
\hline Construct & Item name & Item label & Mean & SD & $\begin{array}{c}\text { Skewn } \\
\text { ess }\end{array}$ & $\begin{array}{c}\text { Kurtos } \\
\text { is }\end{array}$ \\
\hline \multirow{9}{*}{$\begin{array}{l}\text { L2 positive } \\
\text { emotion }\end{array}$} & L2PE_6 & Interested, alert, curious & 3.55 & 0.71 & 0.22 & -0.13 \\
\hline & L2PE_10 & Serene, content, peaceful & 3.46 & 0.76 & -0.08 & 0.19 \\
\hline & L2PE_4 & Hopeful, optimistic, encouraged & 3.44 & 0.73 & 0.18 & 0.09 \\
\hline & L2PE_7 & Joyful, glad, happy & 3.43 & 0.72 & 0.19 & 0.15 \\
\hline & L2PE_1 & Amused, fun-loving, silly & 3.25 & 0.62 & 0.26 & 0.82 \\
\hline & L2PE_8 & Love, closeness, trust & 3.22 & 0.79 & -0.08 & 0.24 \\
\hline & L2PE_5 & Inspired, uplifted, elevated & 3.2 & 0.68 & 0.26 & 0.54 \\
\hline & L2PE_9 & Proud, confident, self-assured & 3.18 & 0.76 & 0.25 & 0.6 \\
\hline & L2PE_3 & Grateful, appreciative, thankful & 3.11 & 0.93 & -0.15 & 0.14 \\
\hline \multirow{11}{*}{$\begin{array}{l}\text { L3 positive } \\
\text { emotion }\end{array}$} & L2PE_2 & Awe, wonder, amazement & 3.04 & 0.83 & -0.17 & 0.26 \\
\hline & L3PE_6 & Interested, alert, curious & 3.38 & 0.73 & 0.10 & 0.24 \\
\hline & L3PE_10 & Serene, content, peaceful & 3.24 & 0.76 & 0.06 & 0.36 \\
\hline & L3PE_4 & Hopeful, optimistic, encouraged & 3.19 & 0.77 & 0.01 & 0.39 \\
\hline & L3PE_7 & Joyful, glad, happy & 3.14 & 0.8 & -0.08 & 0.73 \\
\hline & L3PE_1 & Amused, fun-loving, silly & 3.1 & 0.7 & -0.03 & 1.49 \\
\hline & L3PE_8 & Love, closeness, trust & 3.03 & 0.84 & -0.06 & 0.26 \\
\hline & L3PE_2 & Awe, wonder, amazement & 2.94 & 0.82 & -0.09 & 0.34 \\
\hline & L3PE_5 & Inspired, uplifted, elevated & 2.94 & 0.77 & 0.00 & 0.67 \\
\hline & L3PE_9 & Proud, confident, self-assured & 2.84 & 0.79 & 0.05 & 0.39 \\
\hline & L3PE_3 & Grateful, appreciative, thankful & 2.82 & 0.8 & -0.16 & 0.38 \\
\hline \multirow{2}{*}{$\begin{array}{l}\text { L2 negative } \\
\text { emotion }\end{array}$} & L2NE_10 & Stressed, nervous, overwhelmed & 2.92 & 0.74 & -0.05 & 0.98 \\
\hline & L2NE_1 & Angry, irritated, annoyed & 2.82 & 0.74 & 0.14 & 0.37 \\
\hline
\end{tabular}


Author manuscript | Meng Liu

\begin{tabular}{|c|c|c|c|c|c|c|}
\hline & L2NE_5 & $\begin{array}{l}\text { Embarrassed, self-conscious, } \\
\text { blushing }\end{array}$ & 2.65 & 0.88 & -0.13 & 0.06 \\
\hline & L2NE_8 & Sad, downhearted, unhappy & 2.65 & 0.78 & 0.18 & 0.73 \\
\hline & L2NE_2 & Ashamed, humiliated, disgraced & 2.5 & 0.93 & 0.02 & -0.4 \\
\hline & L2NE_9 & Scared, fearful, afraid & 2.49 & 0.89 & 0.24 & 0.17 \\
\hline & L2NE_6 & Guilty, repentant, blameworthy & 2.43 & 0.92 & 0.07 & -0.45 \\
\hline & L2NE_7 & Hate, distrust, suspicion & 2.11 & 0.89 & 0.49 & 0.02 \\
\hline & L2NE_4 & Disgust, distaste, revulsion & 1.9 & 0.87 & 0.78 & 0.39 \\
\hline & L2NE_3 & Contemptuous, scornful, disdainful & 1.51 & 0.73 & 1.29 & 1 \\
\hline & L3NE_10 & Stressed, nervous, overwhelmed & 2.89 & 0.8 & 0.09 & 0.46 \\
\hline \multirow{7}{*}{$\begin{array}{l}\text { L3 negative } \\
\text { emotion }\end{array}$} & L3NE_9 & Scared, fearful, afraid & 2.68 & 0.9 & -0.01 & -0.08 \\
\hline & L3NE_8 & Sad, downhearted, unhappy & 2.63 & 0.82 & 0.01 & -0.05 \\
\hline & L3NE_1 & Angry, irritated, annoyed & 2.54 & 0.8 & 0.00 & -0.11 \\
\hline & L3NE_5 & $\begin{array}{l}\text { Embarrassed, self-conscious, } \\
\text { blushing }\end{array}$ & 2.25 & 0.88 & 0.03 & -0.73 \\
\hline & L3NE_2 & Ashamed, humiliated, disgraced & 2.23 & 0.85 & 0.16 & -0.51 \\
\hline & L3NE_6 & Guilty, repentant, blameworthy & 2.13 & 0.88 & 0.28 & -0.52 \\
\hline & L3NE_7 & Hate, distrust, suspicion & 1.95 & 0.84 & 0.51 & -0.3 \\
\hline \multirow{8}{*}{$\begin{array}{l}\text { Ideal } \\
\text { multilingual } \\
\text { self }\end{array}$} & L3NE_4 & Disgust, distaste, revulsion & 1.81 & 0.82 & 0.62 & -0.43 \\
\hline & L3NE_3 & Contemptuous, scornful, disdainful & 1.54 & 0.72 & 1.06 & 0.14 \\
\hline & IMS_4 & $\begin{array}{l}\text { Using different foreign languages } \\
\text { will be a part of my future. }\end{array}$ & 4.47 & 1.03 & -0.29 & -0.04 \\
\hline & IMS_5 & $\begin{array}{l}\text { I can imagine myself using more } \\
\text { than one foreign language in my } \\
\text { future career. }\end{array}$ & 4.16 & 1.06 & -0.09 & -0.31 \\
\hline & IMS_3 & $\begin{array}{l}\text { I can imagine myself using more } \\
\text { than one foreign language in many } \\
\text { scenarios in the future. }\end{array}$ & 4.15 & 1.08 & -0.18 & -0.19 \\
\hline & IMS_6 & $\begin{array}{l}\text { I can imagine myself living abroad, } \\
\text { using different foreign languages to } \\
\text { communicate with people. }\end{array}$ & 4.04 & 1.12 & -0.12 & -0.42 \\
\hline & IMS_1 & $\begin{array}{l}\text { I think I will become a person who } \\
\text { uses multiple languages in the } \\
\text { future. }\end{array}$ & 4.03 & 1.1 & -0.17 & -0.37 \\
\hline & IMS_2 & $\begin{array}{l}\text { Using different foreign languages } \\
\text { to communicate with people will } \\
\text { not be too difficult for me in the } \\
\text { future. }\end{array}$ & 3.82 & 1.08 & 0.00 & -0.21 \\
\hline
\end{tabular}



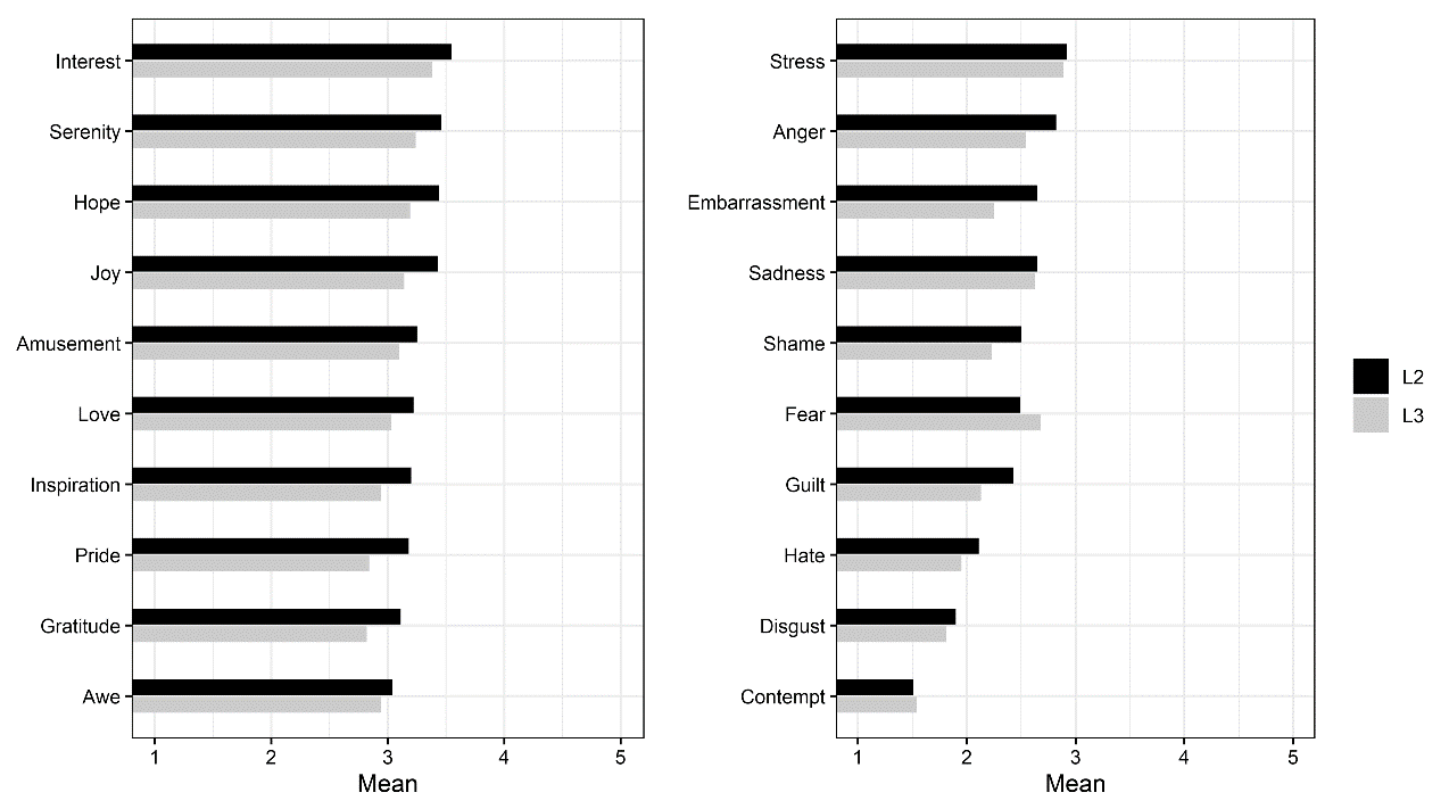

Figure 2 Grouped bar chart of language learning emotions. Individual emotions are sorted according to English (L2) learning emotions in descending order.

Before proceeding to the main analysis, a multivariate normality test (Mardia's test) was performed using the MVN package (Korkmaz et al., 2014) in R to determine the most appropriate estimator for subsequent analysis (e.g., maximum likelihood estimation assumes multivariate normality). The results showed that the data were not multivariate normal, (skewness (23479.22, $\mathrm{p}<.001)$, kurtosis (47.94, $\mathrm{p}<.001)$ ). Accordingly, in subsequent analysis, weighted least square mean and variance adjusted (WLSMV) estimator was chosen as it is a recommended robust estimator (B. Muthén, 1997) for non-normal and categorical data.

\section{RQ1 To what extent can convergent and discriminant validity of the ideal}

\section{multilingual self be established?}

To fully establish the convergent and discriminant validity of the ideal multilingual self, all five constructs in the current study were simultaneously examined in the measurement model. Given that items for English (L2) and LOTEs (L3) emotions share the same wording except for the target language, method effect covariances were specified in the measurement model a priori by allowing paired residual covariances 
between items measuring the same emotion in L2 and L3 (e.g., residual covariance between items measuring 'Amusement': L2PE_1 and L3PE_1). Even though not all residual covariances were statistically significant (Table 2), all paths for method effect were retained in the model to enhance generalisability. Two items ('Awe' in L2 and L3 learning: L2PE_2, L3PE_2) were removed from the final measurement model due to factor loading being lower than .40 . The final measurement model fits the data adequately well $\left(\chi^{2}(873)=1976.114, \mathrm{CFI}=.955, \mathrm{TLI}=.951, \mathrm{RMSEA}=.049(.046-\right.$ $.052), \mathrm{SRMR}=.060)$.

Table 2 Factor loadings and method effects

\begin{tabular}{llrrrrr}
\hline Path & & B & $\beta$ & SE & Z & p \\
\hline L2 positive emotion $\rightarrow$ & L2PE_1 & - & 0.63 & 0.03 & 19.95 & 0.00 \\
& L2PE_3 & 0.95 & 0.60 & 0.03 & 19.75 & 0.00 \\
& L2PE_4 & 1.34 & 0.84 & 0.02 & 47.28 & 0.00 \\
& L2PE_5 & 1.18 & 0.74 & 0.03 & 29.51 & 0.00 \\
& L2PE_6 & 1.21 & 0.76 & 0.02 & 37.42 & 0.00 \\
& L2PE_7 & 1.35 & 0.84 & 0.02 & 52.14 & 0.00 \\
& L2PE_8 & 1.29 & 0.81 & 0.02 & 40.77 & 0.00 \\
& L2PE_9 & 1.18 & 0.74 & 0.02 & 33.60 & 0.00 \\
& L2PE_10 & 1.02 & 0.64 & 0.03 & 23.53 & 0.00 \\
\hline L2 negative emotion $\rightarrow$ & L2NE_1 & - & 0.75 & 0.02 & 30.70 & 0.00 \\
& L2NE_2 & 0.99 & 0.74 & 0.03 & 29.44 & 0.00 \\
& L2NE_3 & 0.90 & 0.68 & 0.04 & 18.89 & 0.00 \\
& L2NE_4 & 1.03 & 0.77 & 0.03 & 29.73 & 0.00 \\
& L2NE_5 & 0.85 & 0.64 & 0.03 & 22.70 & 0.00 \\
& L2NE_6 & 0.75 & 0.56 & 0.03 & 17.32 & 0.00 \\
& L2NE_7 & 1.02 & 0.77 & 0.02 & 31.92 & 0.00 \\
& L2NE_8 & 0.96 & 0.72 & 0.03 & 27.80 & 0.00 \\
& L2NE_9 & 0.96 & 0.72 & 0.02 & 29.51 & 0.00 \\
& L2NE_10 & 0.95 & 0.71 & 0.03 & 25.46 & 0.00 \\
\hline L3 negative emotion $\rightarrow$ & L3PE_1 & - & 0.58 & 0.03 & 18.10 & 0.00 \\
& L3NE_1 & - & 0.75 & 0.02 & 34.34 & 0.00 \\
& L3NE_2 & 1.08 & 0.81 & 0.02 & 45.84 & 0.00
\end{tabular}




\begin{tabular}{|c|c|c|c|c|c|c|}
\hline & L3NE_3 & 1.03 & 0.77 & 0.03 & 31.06 & 0.00 \\
\hline & L3NE_4 & 1.15 & 0.86 & 0.02 & 48.28 & 0.00 \\
\hline & L3NE_5 & 0.99 & 0.74 & 0.03 & 30.14 & 0.00 \\
\hline & L3NE_6 & 0.94 & 0.70 & 0.02 & 29.13 & 0.00 \\
\hline & L3NE_7 & 1.07 & 0.80 & 0.02 & 41.82 & 0.00 \\
\hline & L3NE_8 & 0.88 & 0.66 & 0.03 & 24.57 & 0.00 \\
\hline & L3NE_9 & 0.86 & 0.65 & 0.03 & 23.04 & 0.00 \\
\hline & L3NE_10 & 0.85 & 0.63 & 0.03 & 22.88 & 0.00 \\
\hline \multirow[t]{6}{*}{ Ideal multilingual self $\rightarrow$} & MLIS_1 & - & 0.84 & 0.01 & 84.76 & 0.00 \\
\hline & MLIS_2 & 0.87 & 0.75 & 0.02 & 31.47 & 0.00 \\
\hline & MLIS_3 & 1.06 & 0.90 & 0.01 & 122.08 & 0.00 \\
\hline & MLIS_4 & 0.80 & 0.68 & 0.01 & 49.37 & 0.00 \\
\hline & MLIS_5 & 1.08 & 0.92 & 0.00 & 275.26 & 0.00 \\
\hline & MLIS_6 & 1.04 & 0.89 & 0.01 & 84.65 & 0.00 \\
\hline \multicolumn{7}{|l|}{ Method effects } \\
\hline L2PE_1 WITH L3PE_1 & & 0.05 & 0.09 & 0.07 & 1.21 & 0.23 \\
\hline L2PE_3 WITH L3PE_3 & & 0.27 & 0.40 & 0.05 & 7.86 & 0.00 \\
\hline L2PE_4 WITH L3PE_4 & & -0.03 & -0.12 & 0.12 & -1.01 & 0.31 \\
\hline L2PE_5 WITH L3PE_5 & & 0.07 & 0.17 & 0.08 & 2.08 & 0.04 \\
\hline L2PE_6 WITH L3PE_6 & & 0.01 & 0.03 & 0.08 & 0.40 & 0.69 \\
\hline L2PE_7 WITH L3PE_7 & & 0.09 & 0.36 & 0.11 & 3.22 & 0.00 \\
\hline L2PE_8 WITH L3PE_8 & & 0.02 & 0.06 & 0.08 & 0.79 & 0.43 \\
\hline L2PE_9 WITH L3PE_9 & & 0.12 & 0.25 & 0.06 & 3.98 & 0.00 \\
\hline L2PE_10 WITH L3PE_10 & & 0.12 & 0.24 & 0.06 & 3.95 & 0.00 \\
\hline L2NE_1 WITH L3NE_1 & & 0.01 & 0.02 & 0.07 & 0.32 & 0.75 \\
\hline L2NE_2 WITH L3NE_2 & & 0.12 & 0.29 & 0.08 & 3.90 & 0.00 \\
\hline L2NE_3 WITH L3NE_3 & & 0.26 & 0.55 & 0.09 & 6.44 & 0.00 \\
\hline L2NE_4 WITH L3NE_4 & & 0.06 & 0.18 & 0.10 & 1.85 & 0.07 \\
\hline L2NE_5 WITH L3NE_5 & & 0.16 & 0.32 & 0.07 & 4.88 & 0.00 \\
\hline L2NE_6 WITH L3NE_6 & & 0.14 & 0.24 & 0.05 & 4.54 & 0.00 \\
\hline L2NE_7 WITH L3NE_7 & & 0.13 & 0.34 & 0.08 & 4.54 & 0.00 \\
\hline L2NE_8 WITH L3NE_8 & & 0.03 & 0.05 & 0.06 & 0.88 & 0.38 \\
\hline L2NE_9 WITH L3NE_9 & & 0.11 & 0.21 & 0.06 & 3.32 & 0.00 \\
\hline L2NE_10 WITH L3NE_10 & & 0.07 & 0.12 & 0.06 & 1.97 & 0.05 \\
\hline
\end{tabular}

The construct of the ideal multilingual self, in addition to the emotional constructs, showed good convergent and discriminant validity: All standardised factor loadings were statistically significant $(\mathrm{p}<.001)$ and all above .50 (Table 2). Values of construct reliability were well above .70, and the AVEs all above .50 (Table 3). Discriminant validity was satisfactory because all factor correlations were well below .85 and the square roots of AVEs were higher than the corresponding factor correlations (Table 3). 
Table 3 Reliability, validity and interconstruct correlations for the scales of the measurement model

\begin{tabular}{|c|c|c|c|c|c|c|c|}
\hline Scale & $\mathrm{CR}$ & AVE & L2PE & L2NE & L3PE & L3NE & IMS \\
\hline L2PE & .913 & .541 & .736 & & & & \\
\hline L2NE & .909 & .501 & $-.153 * * *$ & .708 & & & \\
\hline L3PE & .924 & .581 & $.498 * * *$ & $-.104 *$ & .762 & & \\
\hline L3NE & .922 & .546 & -.007 n.s. & $.485^{* * *}$ & $-.216^{* * *}$ & .739 & \\
\hline IMS & .931 & .695 & $.477 * * *$ & $-.159 * * *$ & $.439 * * *$ & $-.058 \mathrm{n} . \mathrm{s}$. & .834 \\
\hline \multicolumn{8}{|c|}{ Note. Values in the diagonal are the square roots of their respective average variance extracted (AVE). } \\
\hline \multicolumn{8}{|c|}{$\mathrm{CR}=$ construct validity $; \mathrm{L} 2 \mathrm{PE}=\mathrm{L} 2$ positive emotion $; \mathrm{L} 2 \mathrm{NE}=\mathrm{L} 2$ negative emotion $; \mathrm{L} 3 \mathrm{PE}=\mathrm{L} 3$ positive emotion; $\mathrm{L} 3 \mathrm{NE}=\mathrm{L} 3$ negative emotion; } \\
\hline \multicolumn{8}{|c|}{ IMS = ideal multilingual self } \\
\hline \multicolumn{8}{|c|}{$* \mathrm{p}<.05 * * * \mathrm{p}<.001$ n.s. non-significant } \\
\hline
\end{tabular}

\section{RQ2 To what extent do positive and negative emotional experiences in English}

\section{(L2) and LOTEs (L3) learning predict the ideal multilingual self?}

To assess the extent to which positive and negative emotion would predict ideal multilingual self, the initial path model (Figure 1) was submitted to Mplus 8.3 for evaluation with WLSMV as the estimator. The model fits the data adequately well $\left(\chi^{2}(873)=1976.114, \mathrm{CFI}=.955, \mathrm{TLI}=.951, \mathrm{RMSEA}=.049(.046-.052), \mathrm{SRMR}=\right.$ .060). Model results are presented Figure 3.

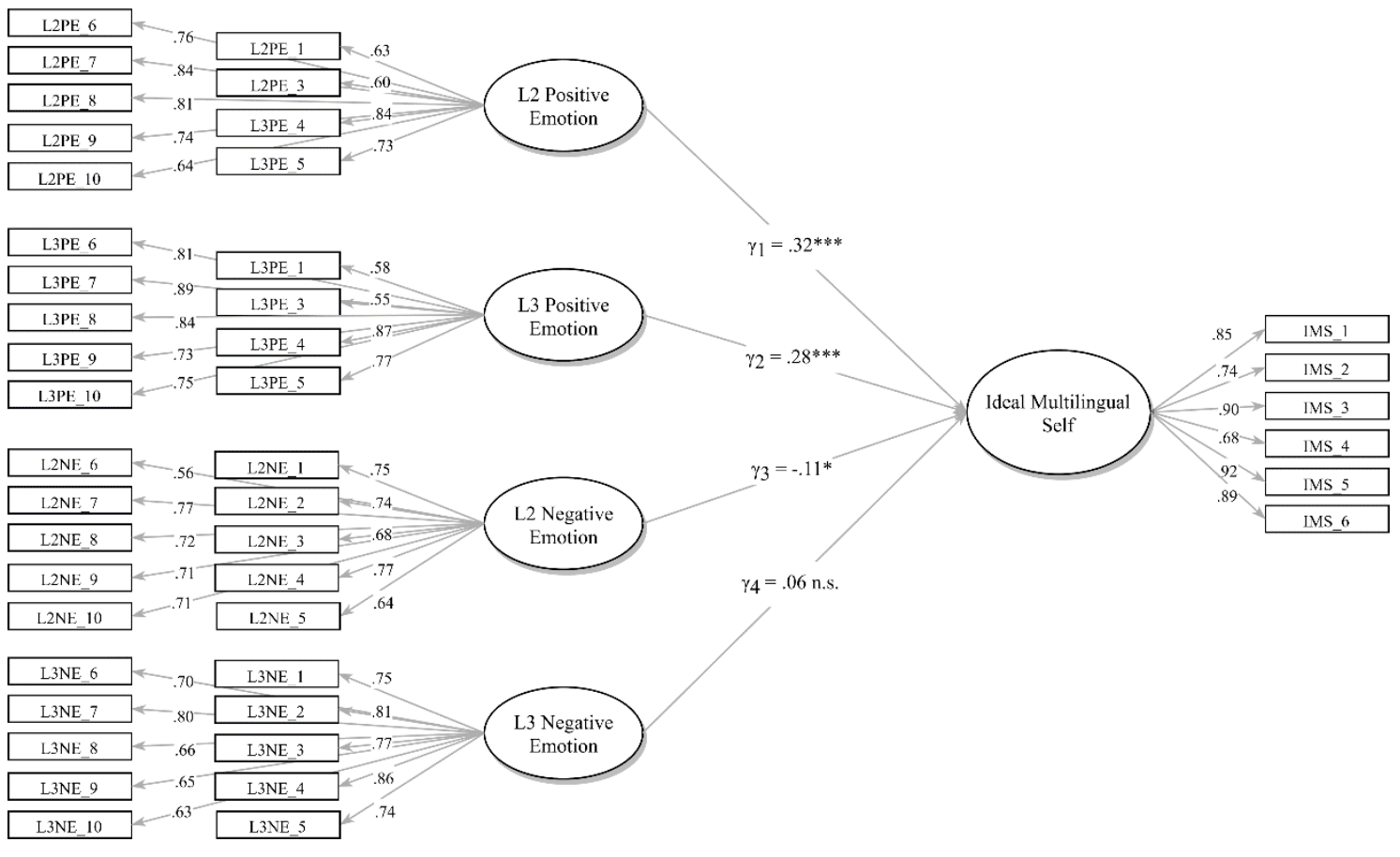


Figure 3. SEM model. Method effects (paired residual covariances) are not shown in the diagram to maintain visual clarity (see Table 1). ***p $<.001$ n.s. nonsignificant.

Overall, the proposed model accounts for $29 \%\left(\mathrm{R}^{2}\right)$ of the variance in the ideal multilingual self. To facilitate a more meaningful and practical interpretation, effect size (ES) was calculated. Specifically, Cohen's $f^{2}$ was used to calculate the global ES in a multiple regression context $\left(f^{2}=\mathrm{R}^{2} / 1-\mathrm{R}^{2}\right)$. According to Cohen's guidelines (1988), the effect size of the model is large $\left(f^{2}=.41\right)$, meaning that positive and negative emotion in English (L2) and LOTEs (L3) account for a meaningful explanatory variance of the ideal multilingual self. In other words, the evidence indicates that there was a substantial link between emotional experience in language learning and the ideal multilingual self.

To examine the unique contribution of positive and negative emotion in each language, four path coefficients were estimated. With the exception of the path from L3 negative emotion to ideal multilingual self $(\gamma 4=.06, p=.21)$, all path coefficients were significant, meaning that all emotional experiences except negative emotion in L3 learning were statistically linked with ideal multilingual self. Specifically, both L2 positive emotion $(\gamma 1=.32, \mathrm{p}<.001)$ and L3 positive emotion $(\gamma 2=.28, \mathrm{p}<.001)$ were positively linked to the ideal multilingual self. In contrast, L2 negative emotion was negatively so $(\gamma 3=-.11, \mathrm{p}<.05)$.

\section{RQ3 Are positive and negative emotion in English (L2) and LOTES (L3) learning equally predictive of the ideal multilingual self?}

To determine whether the contribution of emotional experience to ideal multilingual self is different between English (L2) and LOTEs (L3), path coefficients were formally compared using chi-square difference test: A nested model is set up by constraining the two path coefficients to be equal and model fit statistics (chi-square value) is compared 
with the original model in which the two paths are freely estimated. If the model fit is significantly worsened in the nested model, then it can be concluded that the two paths are not equal. If the model fit does not change significantly (i.e., chi-square difference non-significant) then the two paths are not statistically different.

Comparing the coefficients involving positive emotion in English and in LOTEs learning (null hypothesis $\gamma 1=\gamma 2$ ), the chi-square test result was non-significant $\left(\chi^{2}(1)=\right.$ $0.052, \mathrm{p}=.82$ ). This means that positive emotion in the two languages was shown to similar strength in predicting the ideal multilingual self. The same procedure was applied to test whether the same pattern holds for negative emotion (null hypothesis $\gamma 3=\gamma 4)$ and the chi-square difference was borderline significant $\left(\chi^{2}(1)=3.878, p=\right.$ .0489). This indicates that L2 negative emotion was statistically more predictive of the ideal multilingual self than L3 negative emotion, though the discrepancy between the two links was not very strong.

\section{Discussion}

Situated at the intersection of multilingualism, motivation and emotion, this study is one of the first that empirically assessed the construct validity of the ideal multilingual self in the Chinese context and examined the relationship between a full range of emotions and the ideal multilingual self on simultaneous learners of English (L2) and LOTEs (L3), using latent modelling approach. It supplied initial evidence of the construct validity of the ideal multilingual self in China, utilising relatively large-scale data from language learners at the tertiary level, a further expansion of previous evidence from secondary-level learners in Europe (Henry \& Thorsen, 2018). Findings also suggest an overall significant and meaningful role of emotion in relation to the ideal multilingual self and interesting patterns that indicate potentially critical differences in mechanisms 
between positive and negative emotions that call for more research to further investigate. Particularly, learners experienced positive emotion largely similarly in English and LOTEs learning and the more positive emotion one experiences, the more likely it is that one also has a stronger ideal multilingual self. On the other hand, learners seemed to have different negative emotional experience in learning English and LOTEs and the relationship between negative emotion and multilingual motivation seems to be dependent on the target language. The more negative emotion one experiences in English learning, the weaker the ideal multilingual self, whereas there is no significant relationship between experiencing negative emotions in LOTEs learning and the ideal multilingual self.

\section{Construct validity of the ideal multilingual self}

The results offer support for both the convergent and discriminant validity of the ideal multilingual self. This finding is of importance because it suggests that the construct of ideal multilingual self is applicable, with sufficient psychometric reliability, to simultaneous language learners at ordinary universities in China and that it could be well differentiated from related affective variables such as language learning emotions. This finding also aligns well with previous studies using qualitative data that suggested the applicability of the ideal multilingual self (Z. Wang \& Zheng, 2019; Zheng et al., 2019). Building on this initial evidence, future research could further establish the construct validity by replicating on independent samples in the Chinese context and evaluating the discriminant validity of this construct from other related constructs such as the ideal L2 self (cf. Henry \& Thorsen, 2018 on discriminant validity from the ideal LOTE self). 


\section{Relevance of emotion to the ideal multilingual self}

The overall relevance of emotional experience to motivation was evident in the data. Manifested in the substantial amount of variance in ideal multilingual self being explained by emotion, it is corroborated that emotion could be a key factor in future self-guides (MacIntyre, 2002; MacIntyre et al., 2009, 2020; MacIntyre \& Gregersen, 2012). More importantly, findings in this study indicate potentially critical differences in how positive and negative emotions operate in students' multilingual experience and multilingual motivation. On the one hand, patterns involving positive emotion were largely consistent and a promising link was identified with respect to the ideal multilingual self, all of which warrants further attention to investigate how positive emotion could be more effectively harnessed in classroom practice and echoes the call for more research on the effectiveness of intervention programs drawing on theories in positive psychology (Dewaele et al., 2019; Dewaele \& Li, 2020; MacIntyre, Gregersen, et al., 2019; MacIntyre \& Mercer, 2014). On the other hand, the divergent and less consistent patterns concerning negative emotion could be an indication of more complex functioning of negative emotions and suggests that one individual emotion, such as the well-researched 'anxiety', tells perhaps only part of the story and a more nuanced approach is needed to fully reflect the extent to which different negative emotions feature differently in the learning of different languages, as observed in the difference in the rankings of negative emotions in English and LOTEs learning (cf. Teimouri, 2018 on the differential roles of shame and guilt for example) and in relation to multilingual motivation. 


\section{Positive emotion and the ideal multilingual self}

Positive emotion, regardless of whether target language is English or LOTEs, was experienced more frequently than negative emotion by learners and displayed a significant and positive relationship to the ideal multilingual self. The overall higher frequency of positive than negative emotional experience in both English and LOTEs learning reported in this study echoes and expands on previous findings that found foreign language enjoyment to be more prevalent than anxiety among learners in China (Jiang \& Dewaele, 2019), United Kingdom (Dewaele et al., 2018) and around the world (Dewaele \& MacIntyre, 2014). The positive link between positive emotion and the ideal multilingual self may not be surprising because the ideal self has a promotional focus that is related to the realisation of positive outcome (Higgins, 1998) and positive emotion shares such promotional orientation in that it promotes growth and new learning (Fredrickson, 2003; MacIntyre \& Gregersen, 2012). The congruence of such an orientation makes it plausible that positive emotion experience may function as the source of energy that promotes the aspiration to become multilingual, which lends support to previous theorisation and qualitative evidence (MacIntyre, 2002; MacIntyre et al., 2009; MacIntyre \& Gregersen, 2012). This finding also aligns with previous research using different measurements and across contexts on emotions and the ideal L2 self (MacIntyre, Dewaele, et al., 2019; MacIntyre \& Vincze, 2017; Papi, 2010; Sugita McEown et al., 2014; Teimouri, 2016). The similarity in general patterns in the available studies across different measurement instruments, contexts a nd languages attests to the robustness of the role of positive emotion in enhancing learners' motivational self, not only the lower-level L2 self but also the higher-level multilingual self. 
What is noticeable is the similar manner in which students experienced positive emotions in English and LOTEs learning and the similar strengths of paths from positive emotion in English and LOTEs learning to the ideal multilingual self. Judging from the overall more positive emotional experience in both English and LOTEs learning, and the relatively high mean scores of the ideal multilingual self (Table 1), it could be said that this group of learners in general found the learning of English and LOTEs to be primarily positive and possessed a moderate to strong ideal multilingual self, which aligns with previous research that found English major students to be more multilingually oriented and self-motivated than LOTEs major students at a key university in China (Zheng et al., 2019). It seems that for this group of learners, their positive experiences in learning English and LOTEs were more or less evenly distributed and contributed equally to their motivation to become multilingual. Admittedly, the exact mechanism is difficult to pinpoint given that the sample only included one group of learners and should be further investigated in future research by comparing a greater variety of learners, including those who may be less inclined to learn an additional foreign language and become multilingual.

\section{Negative emotion and the ideal multilingual self}

In contrast to the uniform patterns involving positive emotion, the picture involving negative emotion and the ideal multilingual self appears to tell a different story: There is a small but significant negative relationship between experiencing negative emotions in English learning and the ideal multilingual self whereas no significant relationship was uncovered between negative emotion in LOTEs learning and the ideal multilingual self. This, together with the divergent patterns observed in the emotional item responses (Table 1, Figure 2), suggests that positive and negative emotion do indeed operate in different manners (cf. Dewaele \& MacIntyre, 2014, 2016; MacIntyre et al., 2020; 
MacIntyre \& Gregersen, 2012), and such difference could be dependent upon target languages, a finding that merits further investigation.

Comparing the negative emotional experience in the two languages (Table 1, Figure 2), students reported greater frequency of 'self-conscious emotions' such as embarrassment and shame that implicate the evaluation of the self (Reeve, 2018, p. 348) in English learning than in LOTEs learning. This suggests that the learning of English is more personally relevant to the students than LOTEs. The higher ranking of anger in English than in LOTEs learning also seems to point to the more internal affective stake involved in English learning. Considering the immense instrumental value placed on English in the Chinese context (Z. Wang \& Zheng, 2019), the length of time these learners spent in learning English (primarily over 10 years), and their identity as English major students, the stakes for learning English well are considerably higher than those of LOTEs and thereby challenges and setbacks in learning English would have more profound and farreaching affective implications for this group of learners and potentially jeopardise their sense of self not only in becoming competent English users, but also in becoming multilingual users. In contrast, 'fear' featured more in the LOTEs learning experience, which could be attributed to the compulsory nature of the course (Zhao \& Li, 2014) that imposed external pressure on learners. This divergence in patterns indicates the contrast between the learning of English and LOTEs as differentially internalised, with English being more personally relevant than LOTEs and hence could explain why experiencing negative emotion in learning English, but not LOTEs, could be related to further ramifications such as a lower multilingual motivation, albeit the effect is only small. Still, this manifestation of the negative influence of global English on multilingual learning lends support to previous literature in both China (Zheng et al., 2019) and Europe (Busse, 2017; Csizér \& Lukács, 2010). 


\section{Limitations, research directions and pedagogical implications}

Albeit a step in the right direction, the present study was based on cross-sectional data which only captured the relationship at one moment in time with no intention to confirm causality or generalise over time. To what extent the nature of these relationships vary over time awaits further research and the findings should be interpreted bearing in mind the dynamic nature of emotion and the existence of ambivalent states (MacIntyre \& Mercer, 2014). Though expanded in range, data on emotional experience in language learning were collected on a general level, meaning there was a lack of data on more contextualised information such as the trigger for specific emotional experience. Future research could focus on individual emotions less featured in current literature to develop more in-depth scales to capture the relationship between emotions and motivation.

Despite its limitations, this study provides new evidence of the validity of the ideal multilingual self in the Chinese context and unveils the complexity in the emotionmotivation link from a multilingual perspective. Particularly, it examined the emotional basis of a higher-order motivational construct (i.e., the ideal multilingual self) by including two languages within a learner's linguistic system and supplied evidence of the relevance and complexity of positive and negative emotion captured by a variety of individual emotions. Evident in the varying patterns involving different emotions in learning different languages, a more nuanced understanding was developed that further confirmed the two dimensions of emotion are not merely the 'two faces of Janus' (Dewaele \& MacIntyre, 2014; MacIntyre \& Gregersen, 2012) but could influence motivation in differing manners. The power of positive emotional experience should be harnessed more by both English and LOTEs classroom teachers as positive emotion in learning both languages contributes equally to multilingual motivation while the potential harm of negative emotion in English learning on multilingual motivation 
should be heeded especially by English teachers. Again, the complexity of relationships between emotion and multilingual motivation, as illustrated in this study, calls for a holistic and multilingual educational approach (Fisher et al., 2018; Haukås, 2016; Henry \& Thorsen, 2018) whereby teachers of different languages and subjects coordinate their efforts in motivating language learners and facilitating multilingual learning.

\section{Acknowledgements}

I would like to thank the editors and anonymous reviewers for their insights and advice. I would also like to thank the teachers and participants involved in this project for their generous help and sharing. My gratitude goes to Linda Fisher, Jinshi Shao and Tianyi Wang for their insightful comments on earlier versions of the manuscript and to MariaTherese Friehs for her valuable feedback on statistical analysis.

\section{Funding}

This work was supported by China Scholarship Council [Grant No. 201808310112].

\section{ORCID}

Meng Liu https://orcid.org/0000-0001-8323-2699

\section{References}

Aronin, L. (2016). Multi-competence and dominant language constellation. In V. Cook \& L. Wei (Eds.), The Cambridge handbook of linguistic multi-competence (pp. 142-163). Cambridge University Press. https://doi.org/10.1017/CBO9781107425965.007

Baumgartner, H., Pieters, R., \& Bagozzi, R. P. (2008). Future-oriented emotions: Conceptualization and behavioral effects. European Journal of Social Psychology, 38(4), 685-696. 
Boo, Z., Dörnyei, Z., \& Ryan, S. (2015). L2 motivation research 2005-2014:

Understanding a publication surge and a changing landscape. System, 55, 145157. https://doi.org/10.1016/j.system.2015.10.006

Brown, T. A. (2015). Confirmatory factor analysis for applied research. Guilford Publications.

Busse, V. (2017). Plurilingualism in Europe: Exploring attitudes toward English and other European languages among adolescents in Bulgaria, Germany, the Netherlands, and Spain. The Modern Language Journal, 101(3), 566-582. https://doi.org/10.1111/modl.12415

Cohen, J. (1988). Statistical power analysis for the behavioral sciences. Routledge.

Conway, A. M., Tugade, M. M., Catalino, L. I., \& Fredrickson, B. L. (2013). The broaden-and-build theory of positive emotions: Form, function, and mechanisms. In S. David, I. Boniwell, \& A. C. Ayers (Eds.), The Oxford handbook of happiness. Oxford University Press. https://doi.org/10.1093/oxfordhb/9780199557257.013.0003

Csizér, K., \& Lukács, G. (2010). The comparative analysis of motivation, attitudes and selves: The case of English and German in Hungary. System, 38(1), 1-13. https://doi.org/10.1016/j.system.2009.12.001

Dewaele, J.-M., Chen, X., Padilla, A. M., \& Lake, J. (2019). The Flowering of Positive Psychology in Foreign Language Teaching and Acquisition Research. Frontiers in Psychology, 10, 2128. https://doi.org/10.3389/fpsyg.2019.02128

Dewaele, J.-M., \& Li, C. (2020). Emotions in second language acquisition: A critical review and research agenda. Foreign Language World, 196(1), 34-49. 
Dewaele, J.-M., \& MacIntyre, P. D. (2014). The two faces of Janus? Anxiety and enjoyment in the foreign language classroom. Studies in Second Language Learning and Teaching, 2(4), 237-274. https://doi.org/10.14746/ssllt.2014.4.2.5

Dewaele, J.-M., \& MacIntyre, P. D. (2016). Foreign language enjoyment and foreign language classroom anxiety. The right and left feet of FL learning? In P. D. Macintyre, T. Gregersen, \& S. Mercer (Eds.), Positive psychology in SLA (pp. 215-236). Multilingual Matters.

Dewaele, J.-M., Witney, J., Saito, K., \& Dewaele, L. (2018). Foreign language enjoyment and anxiety: The effect of teacher and learner variables. Language Teaching Research, 22(6), 676-697. https://doi.org/10.1177/1362168817692161

Dörnyei, Z. (2005). The psychology of the language learner: Individual differences in second language acquisition. Lawrence Erlbaum.

Dörnyei, Z. (2009). The L2 motivational self system. In Z. Dörnyei \& E. Ushioda (Eds.), Motivation, language identity and the L2 self (pp. 9-42). Multilingual Matters.

Dörnyei, Z., \& Al-Hoorie, A. H. (2017). The motivational foundation of learning languages other than global English: Theoretical issues and research directions. The Modern Language Journal, 101(3), 455-468. https://doi.org/10.1111/modl.12408

Dörnyei, Z., \& Csizér, K. (2002). Some dynamics of language attitudes and motivation: Results of a longitudinal nationwide survey. Applied Linguistics, 23(4), 421462.

Dörnyei, Z., Csizér, K., \& Németh, N. (2006). Motivation, language attitudes and globalisation: A Hungarian perspective. Multilingual Matters. 
Dörnyei, Z., Henry, A., \& MacIntyre, P. D. (2015). Motivational dynamics in language learning. Multilingual Matters.

Dörnyei, Z., \& Ryan, S. (2015). The psychology of the language learner revisited. Routledge.

Dörnyei, Z., \& Taguchi, T. (2010). Questionnaires in second language research: Construction, administration, and processing. Routledge.

Dörnyei, Z., \& Ushioda, E. (2009). Motivation, language identities and the L2 self: Future research directions. In Z. Dörnyei \& E. Ushioda (Eds.), Motivation, language identity and the L2 self (pp. 350-356). Multilingual Matters.

Fisher, L., Evans, M., Forbes, K., Gayton, A., \& Liu, Y. (2018). Participative multilingual identity construction in the languages classroom: A multitheoretical conceptualisation. International Journal of Multilingualism, 1-19. https://doi.org/10.1080/14790718.2018.1524896

Fornell, C., \& Larcker, D. F. (1981). Evaluating structural equation models with unobservable variables and measurement error. Journal of Marketing Research, $18(1), 39-50$.

Fredrickson, B. L. (2001). The role of positive emotions in positive psychology: The broaden-and-build theory of positive emotions. American Psychologist, 56(3), 218.

Fredrickson, B. L. (2003). The value of positive emotions: The emerging science of positive psychology is coming to understand why it's good to feel good. American Scientist, 91(4), 330-335.

Fredrickson, B. L. (2004). The broaden-and-build theory of positive emotions. Philosophical Transactions of the Royal Society of London. Series B: Biological Sciences, 359(1449), 1367-1377. 
Gao, X., \& Zheng, Y. (2019). Multilingualism and higher education in Greater China. Journal of Multilingual and Multicultural Development, 40(7), 555-561. https://doi.org/10.1080/01434632.2019.1571073

Gardner, R. C. (1985). Social psychology and second language learning: The role of attitudes and motivation. Edward Arnold.

Gardner, R. C. (2010). Motivation and second language acquisition: The socioeducational model. Peter Lang.

Hair, J. F., Black, W. C., Babin, B. J., \& Anderson, R. E. (2013). Multivariate data analysis: Pearson new international edition. Pearson Education Limited.

Haukås, Å. (2016). Teachers’ beliefs about multilingualism and a multilingual pedagogical approach. International Journal of Multilingualism, 13(1), 1-18. https://doi.org/10.1080/14790718.2015.1041960

Henry, A. (2010). Contexts of possibility in simultaneous language learning: Using the L2 motivational self system to assess the impact of global English. Journal of Multilingual and Multicultural Development, 31(2), 149-162. https://doi.org/10.1080/01434630903471439

Henry, A. (2011). Examining the impact of L2 English on L3 selves: A case study. International Journal of Multilingualism, 8(3), 235-255. https://doi.org/10.1080/14790718.2011.554983

Henry, A. (2017). L2 motivation and multilingual identities. The Modern Language Journal, 101(3), 548-565. https://doi.org/10.1111/modl.12412

Henry, A., \& Thorsen, C. (2018). The ideal multilingual self: Validity, influences on motivation, and role in a multilingual education. International Journal of Multilingualism, 15(4), 349-364. https://doi.org/10.1080/14790718.2017.1411916 
Higgins, E. T. (1987). Self-discrepancy: A theory relating self and affect. Psychological Review, 94(3), 319.

Higgins, E. T. (1998). Promotion and prevention: Regulatory focus as a motivational principle. Advances in Experimental Social Psychology, 30, 1-46. https://doi.org/10.1016/S0065-2601(08)60381-0

Hu, L., \& Bentler, P. M. (1999). Cutoff criteria for fit indexes in covariance structure analysis: Conventional criteria versus new alternatives. Structural Equation Modeling: A Multidisciplinary Journal, 6(1), 1-55.

Jiang, Y., \& Dewaele, J.-M. (2019). How unique is the foreign language classroom enjoyment and anxiety of Chinese EFL learners? System. https://doi.org/10.1016/j.system.2019.02.017

Korkmaz, S., Goksuluk, D., \& Zararsiz, G. (2014). MVN: An R package for assessing multivariate normality. The R Journal, 6(2), 151-162.

MacIntyre, P. D. (2002). Motivation, anxiety and emotion in second language acquisition. In P. Robinson (Ed.), Individual differences and instructed language learning (Vol. 2, pp. 45-68). John Benjamins Publishing Company.

MacIntyre, P. D., Dewaele, J.-M., Macmillan, N., \& Li, C. (2019). The emotional underpinnings of Gardner's attitudes and motivation test battery. Contemporary Language Motivation Theory, 60, 57-79.

MacIntyre, P. D., \& Gregersen, T. (2012). Emotions that facilitate language learning: The positive-broadening power of the imagination. Studies in Second Language Learning and Teaching, 2(2), 193. https://doi.org/10.14746/ssllt.2012.2.2.4

MacIntyre, P. D., Gregersen, T., \& Mercer, S. (2019). Setting an agenda for positive psychology in SLA: Theory, practice, and research. The Modern Language Journal, 103(1), 262-274. https://doi.org/10.1111/modl.12544 
MacIntyre, P. D., MacKinnon, S. P., \& Clément, R. (2009). The baby, the bathwater, and the future of language learning motivation research. In Z. Dörnyei \& E. Ushioda (Eds.), Motivation, language identity and the L2 self (pp. 43-65).

MacIntyre, P. D., \& Mercer, S. (2014). Introducing positive psychology to SLA. Studies in Second Language Learning and Teaching, 2, 153-172. https://doi.org/10.14746/ssllt.2014.4.2.2

MacIntyre, P. D., Ross, J., \& Clément, R. (2020). Emotions are motivating. In M. Lamb, K. Csizér, A. Henry, \& S. Ryan (Eds.), The palgrave handbook of motivation for language learning (pp. 183-202). Palgrave Macmillan.

MacIntyre, P. D., \& Vincze, L. (2017). Positive and negative emotions underlie motivation for L2 learning. Studies in Second Language Learning and Teaching, 7(1), 61. https://doi.org/10.14746/ssllt.2017.7.1.4

Markus, H., \& Nurius, P. (1986). Possible selves. American Psychologist, 41(9), 954.

May, S. (2019). Negotiating the multilingual turn in SLA. The Modern Language Journal, 103, 122-129. https://doi.org/10.1111/modl.12531

Mendoza, A., \& Phung, H. (2019). Motivation to learn languages other than English: A critical research synthesis. Foreign Language Annals, 52(1), 121-140. https://doi.org/10.1111/flan.12380

Muthén, B. (1997). Robust inference using weighted least squares and quadratic estimating equations in latent variable modeling with categorical and continuous outcomes. Psychometrika.

Muthén, L., \& Muthén, B. (2019). Mplus user's guide (1998-2019). Muthén \& Muthén: Los Angeles, CA. 
Papi, M. (2010). The L2 motivational self system, L2 anxiety, and motivated behavior:

A structural equation modeling approach. System, 38(3), 467-479. https://doi.org/10.1016/j.system.2010.06.011

R Core Team. (2020). R: A Language and Environment for Statistical Computing. $R$ Foundation for Statistical Computing: Vienna. https://www.R-project.org/.

Raykov, T. (2004). Point and interval estimation of reliability for multiple-component measuring instruments via linear constraint covariance structure modeling. Structural Equation Modeling, 11(3), 342-356.

Reeve, J. (2018). Understanding motivation and emotion (7th ed.). John Wiley \& Sons. Siridetkoon, P., \& Dewaele, J.-M. (2018). Ideal self and ought-to self of simultaneous learners of multiple foreign languages. International Journal of Multilingualism, 15(4), 313-328. https://doi.org/10.1080/14790718.2017.1293063

Sugita McEown, M., Noels, K. A., \& Chaffee, K. E. (2014). At the interface of the socio-educational model, self-determination theory and the L2 motivational self system models. In K. Csizér \& M. Magid (Eds.), The impact of self-concept on language learning (pp. 19-50). Multilingual Matters.

Teimouri, Y. (2016). L2 selves, emotions, and motivated behaviors. Studies in Second Language Acquisition, 39(4), 681-709. https://doi.org/10.1017/S0272263116000243

Teimouri, Y. (2018). Differential roles of shame and guilt in 12 learning: How bad is bad? The Modern Language Journal, 102(4), 632-652. https://doi.org/10.1111/modl.12511

Ushioda, E. (2017). The impact of global english on motivation to learn other languages: Toward an ideal multilingual self. The Modern Language Journal, 101(3), 469-482. https://doi.org/10.1111/modl.12413 
Wang, J. (2015). On curriculum design of the national standards for undergraduate

English-major students: Review and reflections. Modern Foreign Languages, 1, $121-130$.

Wang, Z., \& Zheng, Y. (2019). Chinese university students' multilingual learning motivation under contextual influences: A multi-case study of Japanese majors. International Journal of Multilingualism, 1-18. https://doi.org/10.1080/14790718.2019.1628241

Zhao, J., \& Li, S. (2014). da xue sheng wai yu xue xi dong ji de shi zheng fen xi ji qi shi yi ying yu zhuan ye er wai xue xi dong ji wei li [An empirical study of university students' motivation to learn foreign languages: The case of motivation to learn a second foreign language]. Foreign Language Research, 2, $40-44$.

Zheng, Y., Lu, X., \& Ren, W. (2019). Profiling Chinese university students' motivation to learn multiple languages. Journal of Multilingual and Multicultural Development, 40(7), 590-604. https://doi.org/10.1080/01434632.2019.1571074 